ISSN: 2178-9436

\title{
DA PROBLEMÁTICA DA JUDICIALIZAÇÃO DO RISCO HIDROLÓGICO
}

\author{
OF THE PROBLEM OF JUDICIALIZATION OF HYDROLOGICAL RISK
}

\author{
Adhemar Ronquim Filho \\ Luciana Oranges Cezarino ${ }^{\text {II }}$
}

\begin{abstract}
RESUMO
Os riscos hidrológicos, aumentados em muito nos últimos anos por alguns períodos de seca, influenciaram muitas decisões judiciais que causaram inadimplência no Mercado de Curto Prazo, o qual ficou paralisado ante a dificuldade de cumprimentos nos contratos da Câmara de Comercialização de Energia Elétrica. O busílis estabelece-se na medida em que os geradores, atingidos por períodos de seca, e sem garantia institucionais, buscam a intervenção do Poder Judiciário, o qual, muitos casos, intervêm, concedendo liminares, suspendendo previamente a obrigação de cumprir o contrato de fornecimento de energia. A partir destas decisões, as contratações efetuadas não são cumpridas e os adquirentes são surpreendidos, não recebendo o convencionado, e, por seu turno, também buscam o acolhimento judicial para minimizar seus prejuízos. Neste contexto, surge o presente trabalho, trazendo um pouco da estruturação do setor, o que sintetiza o porquê qualquer intervenção de terceiro na relação desequilibra o arranjo contratual e os órgãos intervenientes. É trazida a recente Lei que traz uma solução para a situação da judicialização desenfreada, buscando garantir aos geradores mais estabilidade e segurança ante aos riscos que perdurarão com os momentos de menor precipitação hídrica, bem como aos adquirentes.
\end{abstract}

Palavras-chave: Câmara de Comercialização de Energia Elétrica. Energia. Segurança Energética. Usinas Hidrelétricas.

\begin{abstract}
Hydrological risks, greatly increased in recent years by some periods of drought, influenced many court decisions that caused default in the Short-term market, which was paralyzed by the difficulty of complying with Electricity Trading Chamber contracts. The rub is established to the extent that generators, hit by periods of drought, and without institutional guarantees, seek the intervention of the Judiciary, which, in many cases, intervene, granting injunctions, previously suspending the obligation to fulfill the contract of Energy supply. Based on these decisions, the contracts made are not fulfilled and the purchasers are surprised, not receiving the agreement, and, in turn, they also seek judicial acceptance to minimize their losses. In this context, the present work arises, bringing a little of the structuring of the sector, which summarizes why any intervention by a third party in the relationship unbalances the contractual arrangement and the intervening bodies. The recent Law that brings a solution to the situation of unbridled judicialization is brought, seeking to guarantee generators more

\footnotetext{
I Advogado Corporativo, Mestre em Sustentabilidade, Doutorando em Administração de Organizações na FEARP-USP, Professor da UNIARA. E-mail: adhemar@usp.br.

II Professora adjunta nível II em regime de dedicação exclusiva na Universidade Federal de Uberlândia (UFU). E-mail: lcezarino@gmail.com.
} 


\section{(D) Ciência \& Tecnologia Fatec-JB}

ISSN: 2178-9436

stability and security in the face of the risks that will endure with the moments of lesser water precipitation, as well as to the purchasers.

Keywords: Eletricty Trading Chamber. Energy. Energy Security. Hidroeletric Plants.

Data de submissão do artigo: 14/08/2020.

Data de aprovação do artigo: 17/12/2020.

DOI: $10.52138 /$ citec.v12i1.75

\section{INTRODUÇÃO}

O Brasil pauta sua matriz energética principalmente na geração hidráulica, a qual fica submetida as condições climáticas, o que enseja uma solução para o fator de risco hidrológico Generation Scaling Factor (GSF), o qual representa a diferença para baixo da energia produzida por usinas e a garantia física existente, endividando e fragilizando o setor, sendo a produção passível de variação substancial a partir de situações hidrológicas. Como a geração hidrelétrica tem importância fulcral na matriz energética, tem-se de pontuar que esta depende de fatores não gerenciáveis e sim, de aspectos naturais, como as chuvas (PAIVA, 2018), que influenciam no volume de água dos rios e reservatórios, ou seja, liga-se a um ciclo natural, sem interveniência dos empresários.

As usinas integrantes do Sistema Interligado Nacional (SIN) despacham energia de forma centralizada pelo Operador Nacional do Sistema (ONS), o qual controla a gestão dos riscos hidrológicos daquelas (PORTO, 2018).

O SIN conecta as produção e transmissão de energia elétrica no Brasil, sempre com o fim de maior eficiência, até pelo território continental que se submete a várias condições hidrológicas. Verifica a necessidade e a possibilidade de demanda e energia, devendo equilibrar a utilização dos recursos e a segurança energética, garantindo distribuição e geração regulares, a fim de haja a comercialização por parte do gerador ao consumidor livre ou especial (MARQUES, 2017).

Quanto a exemplos de riscos hidrológicos, estes influenciam toda a extensão territorial do Brasil, visto a existência de períodos longos de chuvas e secas, gerando certa imprevisibilidade, visto uma hidrologia variável, incluindo o fato de que pode haver mais de uma usina em um mesmo rio, podendo ser patente de gerar menos energia, gerando custos aos empreendedores. No biênio 2014-2015 não foi cumprida a previsão de produção de energia, gerando déficit no Mecanismo de Realocação de Energia (MRE), o qual atua como uma instância moderadora, visando a garantir que as usinas cumpram as garantias físicas, com o saldo positivo atingido pelo conjunto dos empreendimentos, visando compartilhar GSF entre os geradores (MANSO et al., 2010), obrigando os geradores a adquirir de terceiro para cumprir a comercialização energética negociada, ficando as usinas expostas financeiramente (RIBEIRO, 2015).

As Usinas, buscando diminuir os riscos, estabelecem condomínios visando combater riscos hidrológicos expostos no $\mathrm{MRE}$, o qual se pauta por compensação financeira entre os empreendimentos, a fim de que a redução de produção de uma possa ser compensada pelo gerado acima do valor da garantia física pela outra (RODRIGUES, 2018). Esta insegurança pode atingir 40\% (quarenta porcento) do faturamento (DUARTE, 2018), o que é muito acima do aceitável, até porque é afetado por um fenômeno natural, que é a falta de chuvas, restando apenas ao empreendedor a conta a pagar. 


\section{Ciência \& Tecnologia Fatec-JB}

ISSN: 2178-9436

Importante ressaltar que Garantia Física ${ }^{1}$ trata-se do máximo de energia que a usina poderá comercializar, o qual é calculado pela Empresa de Pesquisa Energética (EPE). A usina poderá produzir mais ou menos recursos energéticos, os quais poderão ser comercializados, compondo a garantia física. O condomínio, ao produzir menos, poderá ter sofrido a influência dos riscos hidrológicos, o que significará um déficit na produção.

\section{DA JUDICIALIZAÇÃO DOS RISCOS HIDROLÓGICOS}

Fatores como a estiagem ocorrida nos últimos anos limitaram a expansão de energia com o fim de preservar os reservatórios, mas, como havia muito daquela já comercializada, a não entrega, criou passivo para o empreendimento. A estiagem contribuiu para o desequilíbrio do setor, gerando incerteza no fornecimento de eletricidade, acarretando crise financeira do setor, culminando com a judicialização.

Os períodos de pouca chuva levam à diminuição dos reservatórios em muitas regiões, reduzindo a geração de energia, ocorrendo o GSF, gerando a necessidade de as usinas adquirila no Mercado de Curto Prazo (MCP), para compensar a menor produção. Para mitigar o GSF como risco do gerador, foi repassado ao consumidor, por meio da Bandeira Tarifária vermelha, a partir de dezembro/2015 (SHERMAN, 2018), pautando-se na proporcionalidade entre riscos e a capacidade contributiva, nos termos dos princípios estabelecidos na Lei das Concessões e Permissões Públicas n. ${ }^{\circ}$ 8.987/1995 (BRASIL, 1995). Acerca das bandeiras tarifárias, tem-se (AGÊNCIA NACIONAL DE ENERGIA ELÉTRICA - ANEEL, 2015):

Quadro 1 - Bandeiras tarifárias

\begin{tabular}{|l|l|}
\hline COR & $\begin{array}{l}\text { SIGNIFICADO (sem contar os tributos } \\
\text { vigentes }\end{array}$ \\
\hline Verde & $\begin{array}{l}\text { Condições hidrológicas favoráveis e não } \\
\text { acréscimo nas contas }\end{array}$ \\
\hline Amarela & $\begin{array}{l}\text { Condições um pouco menos favoráveis, com } \\
\text { cobrança adicional de } \mathrm{R} \$ 1,50 \text { por } 100 \mathrm{kwh}\end{array}$ \\
\hline Vermelha & $\begin{array}{l}\text { Condições mais desfavoráveis, variando na } \\
\text { conta de } \mathrm{R} \$ 4,00 \text { a } \mathrm{R} \$ 6,00 \text { por } 100 \mathrm{kwh}\end{array}$ \\
\hline
\end{tabular}

Fonte: elaborada pelos autores com fundamento em Aneel (2015)

O fator GSF pode ser assim representado (mensalmente a Câmara de Comercialização de Energia Elétrica (CCEE) afere a Garantia Física para cada Usina) (SHERMAN, 2018):

$G S F=\left(\frac{\text { Geração Hidráulica }(G W h)_{m}}{\text { Garantia Física }(G W h)_{m}}\right)$

Quanto ao MRE, o qual se trata de um mecanismo de compartilhamento dos riscos hidrológicos, a fim de que o sistema operacional cumpra o seu fim, também de atender a todas

\footnotetext{
${ }^{1}$ Decreto 5.163/2004:

"Artigo 2-(..)

$\S 2^{\circ}$ A garantia física de energia de um empreendimento de geração, a ser definida pelo Ministério de Minas e Energia e a qual deverá constar do contrato de concessão ou do ato de autorização, corresponderá à quantidade máxima de energia elétrica associada ao empreendimento, incluída a importação, que poderá ser utilizada para comprovação de atendimento de carga ou comercialização por meio de contratos."
} 


\section{Ciência \& Tecnologia Fatec-JB}

ISSN: 2178-9436

as usinas, garantindo a otimização do sistema e a segurança do fornecimento de energia ao sistema (JORGE, 2018), existindo três possibilidades previstas (RODRIGUES, 2018):

Quadro 2 - Mecanismo de realocação de energia (MRE)

\begin{tabular}{|c|c|}
\hline SITUAÇÃO & CONSEQUENNCIA \\
\hline $\begin{array}{l}\text { Usina produz menos energia do que a } \\
\text { Garantia Física (déficit) e outra produz mais } \\
\text { do que o previsto (credora) }\end{array}$ & $\begin{array}{l}\text { Pode haver compensação dentro do próprio } \\
\text { MRE, com a devedora pagando Tarifa de } \\
\text { Energia de Otimização (TEO) }\end{array}$ \\
\hline $\begin{array}{l}\text { Usina produz mais energia do que a } \\
\text { Garantia Física, mas a compensação é } \\
\text { inferior do que deveria ser produzida pelo } \\
\text { condomínio }\end{array}$ & $\begin{array}{l}\text { Haverá liquidação das diferenças no } \\
\text { Mercado de curto prazo (MCP), } \\
\text { remunerado pelo Preço de Liquidação das } \\
\text { Diferenças (PLD). }\end{array}$ \\
\hline $\begin{array}{l}\text { Usinas hidrelétricas do Mecanismo de } \\
\text { realocação de energia (MRE) produzem } \\
\text { mais energia do que a soma total das } \\
\text { Garantias Físicas do condomínio }\end{array}$ & $\begin{array}{l}\text { Haverá o rateio dos benefícios da venda da } \\
\text { Energia Secundária }{ }^{2} \text {, remunerada pelo } \\
\text { PLD. }\end{array}$ \\
\hline
\end{tabular}

Fonte: elaborado pelos autores com fundamento em Rodrigues (2018)

Sendo assim, quando toda a energia que foi produzida supera as Garantias Físicas, tem-se um quadro regular e estável; em sendo menor, decorre a instabilidade do setor. (EPE, 2020).

O fato é que a energia que se adquire com base no PLD possui custos maiores, gerando pendências judiciais (CASTRO et al., 2017).

A questão da judicialização dos riscos hidrológicos alcança arcabouço legal com a Lei n. ${ }^{\circ}$ 13.203/2015 (BRASIL, 2018), a qual estabeleceu a previsão de repactuação, conforme Artigo $1 .^{03}$., desde que haja a aceitação da ANEEL. Já neste ato normativo, o novo pacto exige a desistência de eventuais litígios no Judiciário, diferenciando na hipótese de Ambiente de Contratação Regulada (ACR) e Ambiente de Contratação Livre (ACL) (RODRIGUES, 2018):

$\rightarrow \quad$ ACR: risco é realocado ao consumidor mediante pagamento de Prêmio de Realocação a ser pago à Conta Centralizadora dos Recursos de Bandeira Tarifária (CCRBT). Nessa hipótese, é possível haver até mesmo a transferência total do risco mediante a transferência também dos direitos de eventual Energia Secundária; e

ACL: ocorrerá mediante pagamento de Prêmio de Repactuação e contratação de Energia de Reserva ${ }^{4}$ correspondente, no mínimo, a 5\% da Garantia Física da Usina.

No entanto, como as usinas alegam que não criaram o GSF, alegando força maior, procuraram a Justiça buscando obstar que sejam condenadas a pagar valores pelo não fornecimento de energia. Estas demandas, com liminares conseguidas pelos empreendimentos, travariam por volta de R\$ 7 bilhões no mercado (MEYER, 2019), sendo

\footnotetext{
${ }^{2}$ Cunha (2015).

3 "O risco hidrológico suportado pelos agentes de geração hidrelétrica participantes do Mecanismo de Realocação de Energia - MRE poderá ser repactuado pelos geradores, desde que haja anuência da Agência Nacional de Energia Elétrica - ANEEL, com efeitos a partir de $1^{\circ}$ de janeiro de 2015 , mediante contrapartida dos agentes de geração hidrelétrica."

${ }^{4}$ Ferramenta para garantir segurança energética do sistema brasileiro, derivando a energia do que for gerado do ACR.
} 


\section{Ciência \& Tecnologia Fatec-JB}

ISSN: 2178-9436

que, segundo a CCEE, em janeiro de $2018^{5}$, havia por volta de cento e sessenta e cinco liminares judiciais por força do GSF (DUARTE, 2018). Decorrente da judicialização, a qual exsurge da inaceitação dos geradores integrantes do MRE, que detém créditos junto ao MCP sofre em demasia para atingir as receitas a que tem direito. Por outro lado, credores que foram afetados também passaram a buscar o Judiciário para não ter recebíveis limitados de Processos os quais não participaram, o que gera uma celeuma mais grave do que poderia transparecer. A crítica latente é que a regulação vem sendo feita pelo Poder Judiciário, acarretando perda de tempo, prejuízos e instabilidades (COSENZA, 2017).

A gravidade da situação aflora a partir de 2015, período no qual as secas impediram as geradoras de cumprir os contratos, levando o início da busca por liminares judiciais (CONSULTOR JURÍDICO, 2018). Tais empresas não tinham energia contratada para fazer frente à severa escassez de água, turbinada pela má gestão do sistema elétrico (SANTANA, 2019).

\section{DA LEI n. ${ }^{\circ}$ 14.052, DE 08 DE SETEMBRO DE 2020, A QUAL ESTABELECEU NOVAS CONDIÇÕES PARA A REPACTUAÇÃO DO RISCO HIDROLÓGICO DE GERAÇÃO DE ENERGIA ELÉTRICA A FIM DE MINIMIZAR OS IMPACTOS DAS AÇÕES DO JUDICIÁRIO NO SETOR}

Em 08 de setembro de 2020 foi sancionada pelo Presidente da República Jair Bolsonaro a Lei n. ${ }^{\circ}$ 14.052/2020, a qual estabeleceu novas condições para a repactuação do risco hidrológico. Tal Lei dispõe que, caso as usinas renunciassem às liminares, poderia haver o ressarcimento, mediante a extensão das concessões, o que poderia destravar o setor e estimular os investidores, garantir a sustentabilidade e o fortalecimento do ACL, como atributo essencial à política energética nacional (VALADARES, 2019) - artigo $2 .^{\circ}-\mathrm{B}, \S \S 1 .^{\circ} \mathrm{a}$ $3 .^{\circ}-$.

Tal pleito era uma pauta fundamental para a expansão da economia, a fim de encorajar os investimentos ante a dívida do GSF no mercado, visto que calote sempre afasta quem pretende por capital em qualquer atividade que for, e desta feita, a geração de energia é impactada, na medida em que, sem segurança jurídica, qual investidor se animaria?

A Lei, enfim, possui pontos para diminuir a exposição dos empreendimentos a despesas com o GSF, já que decorre de circunstâncias à parte das ações e planejamentos das usinas (POLITO, 2019). Atualmente a judicialização afeta em muito a ACL, não atendendo os interesses dos produtores e comerciantes, bem como atrai uma descomunal insegurança, já que aquele que não está baseado em liminar necessariamente terá uma dívida concretizada (VALADARES, 2019).

A Lei dependerá de regulamentação da ANEEL, visto que a Agência deverá apreciar os cálculos para a fixação do prazo a ser estendido, até porque os geradores deverão aderir às condições (artigo 2. ${ }^{\circ}-\mathrm{C}$ ). Com a Lei, poderá haver a extensão da concessão de usinas como forma de compensação às geradoras com liminares na Justiça, desde que desistam dos processos em andamento (artigo $2 .^{\circ}-\mathrm{A}, 4 .^{\circ}$ a $6 .^{\circ}$ ).

Sobre a novel Lei (ROLIM et al., 2020):

A adesão ao mecanismo de repactuação do risco hidrológico proposto fica condicionada, cumulativamente a: (i) que o agente desista da ação judicial cujo

\footnotetext{
${ }^{5}$ No mês setembro de 2017, não foram pagos R \$ 4,66 bilhões relacionados a liminares de risco hidrológico, referente ao GSF no mercado livre de eletricidade, como também R\$ 880 milhões referentes a outros valores em aberto na liquidação (CCEE, 2017).
} 


\section{Ciência \& Tecnologia Fatec-JB}

ISSN: 2178-9436

objeto seja a isenção ou a mitigação de riscos hidrológicos relacionados ao MRE, renunciando a qualquer alegação de direito sobre o qual se funda a ação; e, (ii) não tenha repactuado o risco hidrológico para a respectiva parcela de energia nos termos propostos em 2015. Nos casos em que o agente não seja litigante, ou não seja apontado como beneficiário no início da ação ajuizada por associação representativa de classe da qual o agente faça parte, a repactuação ficará condicionada à assinatura de termo de compromisso elaborado pela ANEEL, que deverá constar renúncia a qualquer pretensão judicial de limitação percentual de riscos hidrológicos relacionados ao MRE. (...) A expectativa é de que com as novas condições propostas, a lei atraia o interesse dos geradores que não repactuaram o risco hidrológico nos termos propostos em 2015, reduzindo a judicialização associada ao GSF, que atualmente trava mais de $\mathrm{R} \$ 8,6$ bilhões nas operações do mercado de curto prazo da Câmara de Comercialização de Energia Elétrica.

A redução da energia produzida atinge em cheio o faturamento das usinas, clamando por uma "segurança energética" (SHERMAN, 2018), pois, ao contrário, os obstáculos exsurgem para ceifar a expansão da produção nos próximos anos, especialmente em fontes novas e seus custos correspondentes. É tão premente a necessidade de resolver esta problemática que o atual Ministro de Minas e Energia Bento Albuquerque já defendeu em janeiro/2019 que em trinta dias se alcançasse a solução para o GSF (BRITO, 2019).

A insegurança aos projetos atuais e futuros faz com que investidores direcionem recursos para outros projetos. Além da extensão dos contratos como medida mitigadora, uma solução definitiva para a afastar a responsabilidade do empreendimento pelo GSF se faz necessária, a fim de estimular o setor e obstar novas judicializações em sequência futuramente.

A atuação do Judiciário em um ambiente complexo, especializado e bem regulado traz muita incerteza para quem queira manter-se ou ingressar nesta atividade. Sobre o desarranjo assistido (MARQUES, 2017):

\footnotetext{
A significativa exposição financeira compelida aos agentes, neste cenário, fez com que se iniciasse um grande movimento de propositura de ações judiciais voltadas à obtenção de isenção ou limitação de exposição dos índices ou percentuais do GSF, definidos naquele momento. De outro lado, o cumprimento das decisões judiciais no sentido de efetivamente excluir agentes da obrigação de se sujeitarem aos referidos índices provocou o repasse do custo/prejuízo desta exclusão a outros agentes, mediante rateio. Estes, não entendendo legítima a submissão a rateio de custo a que não deram causa, também obtiveram decisões protetivas. Da mesma forma, credores, buscando garantir seus respectivos créditos, igualmente se valeram da proteção judicial. Assim foi se formando um grande passivo e desfalque financeiro no mercado de energia, e, como consequência, configurou-se efetivo travamento sistêmico na contabilização e liquidação da compra e venda de energia realizada perante a CCEE.
}

A intervenção do Judiciário vem sendo grave para o setor e demandaria uma atuação distante, como expedido pela Ministra Laurita Vaz no julgamento da Suspensão de Liminar e de Sentença n. ${ }^{\circ} 2.162$ - DF, do Superior Tribunal de Justiça (STJ):

Resta configurada lesão à ordem pública, que resulta da circunstância de que o Poder Judiciário não pode, como na espécie, imiscuir-se na seara Administrativa para, substituindo-se ao órgão regulador competente, em sede de liminar, alterar as regras de um setor altamente marcado por rigorosos critérios técnicos, devendo ser prestigiada a presunção de legalidade do ato administrativo. 


\section{Ciência \& Tecnologia Fatec-JB}

ISSN: 2178-9436

A diminuição da litigiosidade não é a única solução, mas pode contribuir para aperfeiçoar o setor elétrico, especialmente para os empreendedores ter em mente que o avençado será cumprido, até para um desenvolvimento sustentável deste nicho.

De qualquer forma, o setor elétrico brasileiro clama por uma padronização e modernização, mas, sem o equacionamento e sem a judicialização do GSF, seria construir um arranha-céu sem alicerces (DUARTE, 2018). Como hipótese de diminuir a dependência da energia obstada pela judicialização, haveria uma necessidade de valorização da bioeletricidade sucroenergética no sistema elétrico nacional (UNICA, 2017), mas este tema será objeto em outro momento.

\section{CONSIDERAÇÕES FINAIS}

Como exposto no trabalho, a insegurança jurídica do setor energético tem fatores variados, sendo talvez o GSF o mais proeminente, consagrado como os riscos hidrológicos, decorrente de períodos de poucas chuvas, que acarretam diminuição dos reservatórios e menos disponibilidade hídrica para o cumprimento dos contratos, acarretando a busca pela Justiça para se desincumbir das garantias físicas. Outrossim, o consumidor também sofreu com o não fornecimento momentâneo de energia, tendo o custo repassado para ele na forma de bandeira tarifária.

Sendo assim, as liminares liberam os geradores, mas travam o mercado, levando os contratantes a buscarem o Judiciário, acarretando um travamento na expansão do mercado energético brasileiro. Este ponto nodal não avançou nos últimos anos, até a sanção neste ano da Lei que prevê algumas compensações para os empreendimentos que sofram com o GSF, como a extensão das concessões.

Clamava-se por se buscar uma solução institucional para que seja eximida a responsabilidade dos geradores pelos fatores naturais que influam na produção energética, a fim de estimular o setor, bem como trazer segurança jurídica para os contratantes.

Com a procrastinação da solução, o setor vivia indefinições que poderiam agravar mais ainda o quadro. Como medida paliativa, mas não é o objeto do presente trabalho, devese buscar novas fontes energéticas, menos expostas a intempéries, como a bioeletricidade sucroenergética, a qual, além da vantagem citada retro, é barata e possui abundância de matéria-prima, bastando apenas o estímulo institucional.

\section{REFERÊNCIAS}

AGÊNCIA NACIONAL DE ENERGIA ELÉTRICA. Bandeiras tarifárias. 2015. Disponível em: https://www.aneel.gov.br/bandeiras-tarifarias. Acesso em: 02 nov. 2020.

BRASIL. Lei 8.987. Brasília, 1995. Disponível em:

http://www.planalto.gov.br/ccivil_03/leis/L8987compilada.htm\#: :text=Disp\%C3\%B5e\%20s obre $\% 20$ o $\% 20$ regime $\% 20 \mathrm{de}$, Federal $\% 2 \mathrm{C} \% 20 \mathrm{e} \% 20 \mathrm{~d} \% \mathrm{C} 3 \% \mathrm{~A} 1 \% 20$ outras $\% 20$ provid $\% \mathrm{C} 3 \% \mathrm{~A}$ Ancias. Acesso em: 02 nov. 2020.

Lei 13203. Brasília. 2018. Disponível em:

http://www.planalto.gov.br/ccivil_03/_Ato2015-2018/2015/Lei/L13203.htm. Acesso em: 04 jun. 2020. 


\section{Ciência \& Tecnologia Fatec-JB}

ISSN: 2178-9436

.Tribunal de Contas da União. Acórdão n. ${ }^{0}$ 2.656/2014. Plenário. Relator: Ministro José Jorge. Sessão de 01/10/2014. Disponível em https://pesquisa.apps.tcu.gov.br/\#/documento/acordao-completo/*/NUMACORDAO:2.656. Acesso em: 05 jun 2020.

.Tribunal de Contas da União. Acórdão n. ${ }^{\circ}$ 1.361/2018. Plenário. Relator: Ministro Augusto Sherman. Sessão de 18/7/2018. Disponível em: https://pesquisa.apps.tcu.gov.br/\#/documento/acordao-completo/*/NUMACORDAO:1631. Acesso em: 04 jun 2020.

BRITO, Érico H. Garcia de. O almirante e a solução para o risco hidrológico (GSF). 2019. Disponível em https:/www.linkedin.com/pulse/o-almirante-e-solução-para-risco-hidrológicogsf-garcia-de-brito/. Acesso em 05 jun 2020.

CÂMARA DE COMERCIALIZAÇÃO DE ENERGIA ELÉTRICA (CCEE). Liquidação Financeira do MCP movimenta R\$ 2,7 bilhões. São Paulo, 2017. Disponível em: https://www.ccee.org.br/portal/faces/pages_publico/noticias-

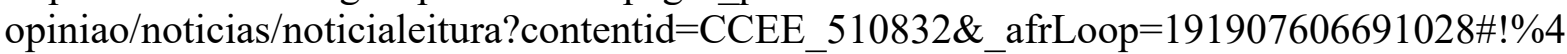
0\%40\%3Fcontentid\%3DCCEE_510832\%26_afrLoop\%3D191907606691028\%26_adf.ctrlstate\%3Da2zec7fgr_49. Acesso em: 09 nov. 2017.

CASTRO, Nivalde de et al.. Análise comparativa internacional e desenhos de mercados atacadistas de energia. Rio de Janeiro: UFRJ, 2017. Disponível em:

http://gesel.ie.ufrj.br/app/webroot/files/publications/25_tdse75.pdf. Acesso em: 02 nov. 2020.

COSENZA, Tiago Lobão. O risco da regulação do setor elétrico pelo Judiciário. 2017. Disponível em: https://www.conjur.com.br/2017-jun-23/tiago-cosenza-risco-regulacao-setoreletrico-judiciario. Acesso em: 04 jun. 2020.

CUNHA, Paulo César Fernandes da. Por que o GSF virou pesadelo? 2015. Disponível em: http://www.fgv.br/fgvenergia/paulo_gsf/files/assets/common/downloads/Paulo_GSF.pdf. Acesso em: 05 jun. 2020.

DUARTE, Nelson. Solução Urgente para o Risco Hidrológico. 2018. Disponível em: https://abrapch.org.br/2018/03/15/solucao-urgente-para-o-risco-hidrologico/. Acesso em: 04 jun. 2020.

EMPRESA DE PESQUISA ENERGÉTICA. Garantia física. Disponível em: https://www.epe.gov.br/pt/areas-de-atuacao/energia-eletrica/expansao-da-geracao/garantiafisica. Acesso em: 02 nov. 2020.

MANSO, Juan Carlos Galvis; FELTRIN, Antonio Padilha; LOYO, Jose Maria Yusta. Valorização da reserva operativa em um ambiente competitivo para geradores hidrelétricos. Sba Controle \& Automação , Campinas, v. 21, n. 5, pág. 439-453, outubro de 2010. Disponível em: http://www.scielo.br/scielo.php?script=sci_arttext\&pid=S0103$17592010000500001 \& \operatorname{lng}=$ en\&nrm=iso. Acesso em: 02 nov. $20 \overline{2} 0$. http://dx.doi.org/10.1590/S0103-17592010000500001. 


\section{Ciência \& Tecnologia Fatec-JB}

ISSN: 2178-9436

MARQUES, Lara Cristina Ribeiro Piau. Efeitos da judicialização das escolhas regulatórias complexas no setor elétrico brasileiro que impactam as liquidações da CCEE / Lara Cristina Ribeiro Piau Marques. - 2017. 151 f. Dissertação (mestrado) - Escola de Direito do Rio de Janeiro da Fundação Getulio Vargas. Orientador: Sérgio Guerra.

MEYER ADVOGADOS, Machado. Solução para GSF destrava Setor Elétrico. Disponível em: https://www.machadomeyer.com.br/pt/imprensa-ij/solucao-para-gsf-destrava-setoreletrico. Acesso em: 04 jun. 2020.

CONSULTOR JURÍDICO. Noronha mantém liminares que reduzem prejuízo de hidrelétricas com seca. Consultor Jurídico, São Paulo, 20 de nov. de 2018. Disponível em: https:/www.conjur.com.br/2018-nov-20/stj-mantem-liminares-reduzem-prejuizohidreletricas-seca. Acesso em: 04 jun. 2020.

PAIVA, J. L. B. V. B. C. DE. A Regulação do Risco Hidrológico na perspectiva da Teoria Processual Administrativa de Steven Croley. Journal of Law and Regulation, v. 4, n. 2, p. 121-150, 15 out. 2018.

POLITO, Rodrigo. Solução para risco hidrológico embute custo a grande consumidor de energia. Valor Econômico. São Paulo, 03 de jul de 2019. Disponível em: https://www.valor.com.br/brasil/6329623/solucao-para-risco-hidrologico-embute-custogrande-consumidor-de-energia. Acesso em: 04 jun. 2020.

PORTO, Talita. Gestão do risco hidrológico. 2018. Disponível em: https://www.gov.br/fazenda/pt-br/centrais-de-conteudos/apresentacoes/arquivos/2018/gestaodo-risco-hidrologico-18-09-2018. Acesso em: 02 nov. 2020.

RIBEIRO, Luísa Helena Machado. Risco de mercado na comercialização de energia elétrica: uma análise estruturada com foco no ambiente de contratação livre - ACL. São Paulo, 2015. Disponível em: https://www.teses.usp.br/teses/disponiveis/3/3143/tde14072016-111314/publico/LuisaHelenaMachadoRibeiro2015.pdf. Acesso em: 02 nov. 2020.

RODRIGUES, Camila. Risco hidrológico, MRE e GSF. Informativo Justen, Pereira, Oliveira \& Talamini, Curitiba, n. ${ }^{o} 141$, novembro de 2018. Disponível em: http://www.justen.com.br/informativo. Acesso em: 04 jun. 2020.

ROLIM, Maria João C. P. et al. Lei sobre judicialização de risco hidrológico no setor de energia é sancionada com vetos. São Paulo, 2020. Disponível em: https://rolimvlc.com/informes/lei-sobre-judicializacao-de-risco-hidrologico-no-setor-deenergia-e-sancionada-com-vetos/. Acesso em: 02 nov. 2020.

SANTANA, Edvaldo. O Nó do Risco Hidrológico. 2019. Disponível em: http://electraenergy.com.br/o-no-do-risco-hidrologico/. Acesso em: 05 jun. 2020.

SUPERIOR TRIBUNAL DE JUSTIÇA. Suspensão de Liminar e de Sentença n..$^{0}$ 2.162 DF (2016/0167162-9). Relator: Ministra Laurita Vaz. DJ: 02/08/2016. Disponível em: https://stj.jusbrasil.com.br/jurisprudencia/549584953/pet-na-suspensao-de-liminar-e-desentenca-pet-na-sls-2162-df-2016-0167162-9. Acesso em: 05 jun. 2020. 


\section{Ciência \& Tecnologia Fatec-JB}

ISSN: 2178-9436

\section{UNIÃO DA INDÚSTRIA DA CANA-DE-AÇÚCAR (UNICA). Contribuição para a} Consulta Pública MME n. ${ }^{\circ}$ 33/2017. São Paulo, 2017. Disponível em:

http://www.mme.gov.br/web/guest/consultaspublicas?p_auth=obDS6uA1\&p_p_id=consultap ublicaexterna_WAR_consultapublicaportlet $\& p \_p \_$lifecycle $=1 \& p \_p \_s t a t e=$ normal $\& p \_p \_$mod $\mathrm{e}=$ view\&p_p_col_id $=$ column $1 \& p \_p \_c o l \_c o u n t=1 \& \_$consultapublicaexterna_WAR_consultap ublicaportlet_objId $=764 \&$ consultapublicaexterna_WAR_consultapublicaportlet_javax.portle t.action=downloadParticipacao. Acesso em: 09 nov2017.

VALADARES, Gustavo. As amarras da judicialização no desenvolvimento do setor elétrico nacional. Disponível em: http://www.agenciainfra.com/blog/infradebate-as-amarrasda-judicializacao-no-desenvolvimento-do-setor-eletrico-nacional/. Acesso em: 04 jun. 2020. 